\title{
A Method for Measuring the Motility of Bacteria and for Comparing Random and Non-random Motility
}

\author{
By J. ADLER AND MARGARET M. DAHL \\ Departments of Biochemistry and Genetics, University of Wisconsin, \\ Madison, Wisconsin, U.S.A.
}

(Accepted for publication 24 August 1966)

\begin{abstract}
SUMMARY
The motility of Escherichia coli was measured in capillary tubes by determining the distribution of bacteria throughout the tube (the complete assay) or simply by locating the point of furthest advance of the bacteria-the frontier of the migration (the frontier assay). The diffusion of ${ }^{14} \mathrm{C}$-glucose was similarly measured in capillary tubes by determining the distribution of radioactivity throughout the tube. The diffusion of glucose under the conditions used was correctly described by the known diffusion equation. The method gives a measure of the net forward velocity of the bacteria. Interpretations, advantages and disadvantages of these assays are given. The method also gives a measure of the degree of randomness of the motility. When chemotaxis is taking place, a very high proportion of the bacteria leave the origin and migrate as a band. When bands are not allowed to form, by omitting methionine, the motility of the bacteria qualitatively resembled a random process, such as the diffusion of glucose.
\end{abstract}

\section{INTRODUCTION}

A quantitative objective method for measuring the motility of bacteria should be a useful tool for exploring various questions of bacterial movement. Such a method is examined in this paper. The bacteria were introduced at one end of capillary tubes filled with a medium suitable for showing motility, and at various times a tube was marked off into compartments and each compartment sampled to determine how much progess the bacteria had made. In the complete assay, the number of viable bacteria in each compartment was measured by plating and counting colonies. This told how many bacteria had moved how far along the tube. Alternatively, in the frontier assay simply the presence or absence of bacteria in each compartment was determined by incubating the contents of each compartment in broth to see whether or not turbidity developed. This located the furthest point of advance of the bacteriathe frontier of the migration.

The method was used in the work reported here to contrast the motility of bacteria under conditions where a chemotactic band of bacteria formed and moved out into the tube with motility under conditions where such a band did not form. A comparison was made with a known random process - the diffusion of glucose.

Vol. 46, No. 1, was issued 3 February 1967 


\section{METHODS}

Description of assay method. A $10 \mathrm{~cm}$. long melting point capillary tube (Kimax no. $34502,0.8-1.2 \mathrm{~mm}$. internal diameter, Owens-Illinois, Toledo, Ohio) was filled from end B with medium (described below) to $8 \mathrm{~cm}$. from end B (see Fig. 1 for a diagram of the completed assay tube). At end B, agar was then added by plunging the tube into a Petri plate containing hardened agar $(15 \mathrm{~g}$. agar $/ 1$. distilled water, and containing no other components) until the column of liquid had been moved to $1 \mathrm{~mm}$. from end A. This $1 \mathrm{~mm}$. was then filled almost to overflowing with about $10^{5}$ to $10^{6}$ bacteria (prepared as described below) from a drawn-out Pasteur pipette (no. A-2882/B transfer pipette, Clay-Adams, Inc., New York, N.Y.). Next, about $5 \mathrm{~mm}$. agar was added at end $\mathrm{A}$ as before; this resulted in pushing out some of the agar at end $\mathrm{B}$. Finally, the tube was sealed at end A with a 2-3 mm. plug of modelling clay to keep the column of liquid from moving when fractions were removed later.

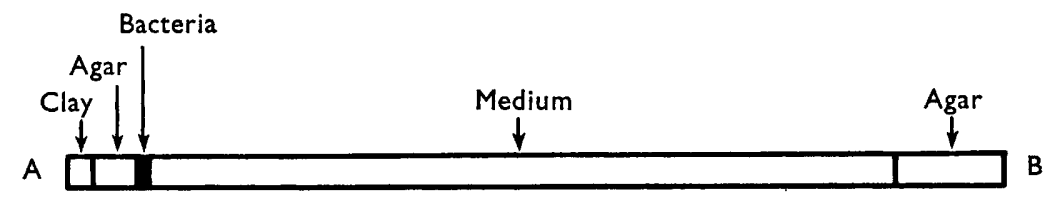

Fig. 1. Description of assay tube. For details see Methods.

The tubes were incubated in a horizontal position at $35^{\circ}$. Recovery of viable bacteria was complete up to $10 \mathrm{hr}$, but incubations longer than $10 \mathrm{hr}$ sometimes resulted in some loss of viability. At the end of the incubation period, each tube was marked off with a pen into ten $8 \mathrm{~mm}$. compartments beginning at the liquid/agar junction (the 'origin') near end A. The tube was then broken at the liquid/agar junction near end B and the contents of each compartment removed one at a time, beginning at end $\mathrm{B}$ with a finely drawn-out Pasteur pipette.

In the complete assay the number of viable bacteria in each compartment was measured by plating áppropriate dilutions on EMB glucose agar, incubating overnight, and then counting colonies. In the frontier assay, the contents of each compartment were added to a tube containing EMB glucose broth and the tubes incubated at $35^{\circ}$ for $28 \mathrm{hr}$. Then the presence or absence of turbidity in each tube was noted.

Organism used. The organism used in this work was a strain of Escherichia coli $\mathrm{K} 12$ called в 275. It was prepared from Dr A. Garen's strain F3-w 1-6, a derivative of the Lederberg strain $\mathrm{w} 1$. Strain в 275 is $\mathrm{F}^{-}$threonine ${ }^{-}$leucine ${ }^{-}$methionine ${ }^{-}$lactose ${ }^{-}$, phosphatase ${ }^{-}$, lysogenic for $\lambda$, resistant to $\lambda$ and $\mathrm{T} 1$, streptomycin-resistant and motile.

The organism was adapted to the growth medium described below by growing once each week at $35^{\circ}$ with rotatory shaking in a New Brunswick Gyrotory shaker to an extinction at $590 \mathrm{~m} \mu\left(E_{590}\right)$ of about 0.8 (about $6 \times 10^{8}$ bacteria/ml.). Longer shaking in this medium caused serious loss in viability. Without any shaking, the bacteria grew poorly in the growth medium and were poorly motile. Shaking speeds anywhere between 100 and $250 \mathrm{rev} . / \mathrm{min}$. (200 rev./min. is the speed usually used) resulted in equally motile cultures. 
Bacteria previously adapted in this way were inoculated into the growth medium described below to give an initial extinction $\left(E_{500}\right)$ value of about 0.04 ; inoculation with lower concentrations of bacteria caused a very long lag period in this medium. The bacteria were incubated at $35^{\circ}$ with rotatory shaking to a final $E_{590}$ of 0.4 (about $3 \times 10^{8}$ bacteria $/ \mathrm{ml}$.).

Then $2.5 \mathrm{ml}$. of the culture were centrifuged for $10 \mathrm{~min}$. at $8000 \mathrm{rev} . / \mathrm{min}$. in the International Centrifuge (head no. 856). The pellet was then gently suspended in $5 \mathrm{ml}$.

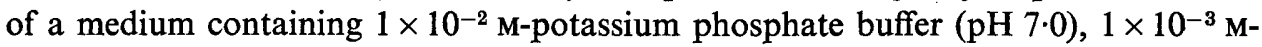
$\mathrm{MgSO}_{4}$ and $1 \times 10^{-4} \mathrm{M}$-EDTA. Again the suspension was centrifuged, the bacteria were resuspended in this medium and again centrifuged, and the supernatant fluid decanted. This final pellet was suspended without any addition of medium by gently shaking the tube, and this suspension served directly as the inoculum for the capillary tubes. More than $90 \%$ of these bacteria were very motile when observed under the microscope. After three additional washes the motility was still excellent, so this washing procedure was safe for preserving the motility.

Media. The inorganic portion of the growth medium contained (g./1.): 11.2, $\mathrm{K}_{2} \mathrm{HPO}_{4} ; 4 \cdot 8, \mathrm{KH}_{2} \mathrm{PO}_{4} ; 2 \cdot 0,\left(\mathrm{NH}_{4}\right)_{2} \mathrm{SO}_{4} ; 0.25, \mathrm{MgSO}_{4} .7 \mathrm{H}_{2} \mathrm{O} ; 0.0005, \mathrm{Fe}_{2}\left(\mathrm{SO}_{4}\right)_{3} ;$ 11 . distilled water; this is the $\mathrm{H}$ medium of Kaiser \& Hogness (1960). The organic portion of this growth medium contained the 20 amino acids commonly encountered

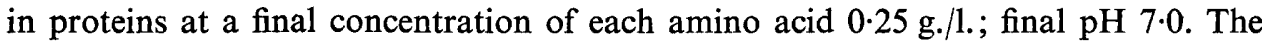
pure amino acids, desirable because they allowed a completely defined medium, could be fully replaced by vitamin-free casein hydrolysate.

The medium used for filling the capillary tubes contained $1 \times 10^{-2} \mathrm{M}$-potassium phosphate buffer (pH 7.0), $1 \times 10^{-4} \mathrm{M}-\mathrm{EDTA}, 1 \times 10^{-3} \mathrm{M}-\mathrm{MgSO}_{4}, 1 \times 10^{-3} \mathrm{M}-\left(\mathrm{NH}_{4}\right)_{2} \mathrm{SO}_{4}$, $1 \times 10^{-2} \mathrm{M}-\mathrm{L}-$-serine; final $\mathrm{pH} 7 \cdot 0$. Only glass-distilled water was used. Serine was chosen as energy source because this strain of Escherichia coli can use serine either aerobically or anaerobically to supply energy for motility (Adler \& Templeton, 1966). This allowed motility to persist everywhere in the tube, even where oxygen had been exhausted. Growth of the bacteria was inhibited in these experiments, since in no case were all three of the required amino acids, leucine, methionine and threonine, added.

EMB glucose broth contained (g./1.): 10, glucose (autoclaved separately); 10, Difco Bacto-Tryptone; $5, \mathrm{NaCl} ; 2, \mathrm{~K}_{2} \mathrm{HPO}_{4} ; 1$, Difco yeast extract; 0.4 , eosin; 0.065 , methylene blue; 11 . of distilled water. EMB glucose agar contained in addition $15 \mathrm{~g}$. agar/l. medium. This is the recipe of Lederberg (1950) modified by Kaiser \& Hogness (1960). The eosin and methylene blue in this case served to discourage the growth of contaminants. As a further precaution, the strain used whenever possible was streptomycin-resistant and in that case streptomycin $(0 \cdot 1 \mathrm{~g} . / 1$.) was added to the EMB glucose broth and to the EMB glucose agar.

\section{RESULTS}

Before the results with bacteria are presented, the diffusion of glucose under conditions identical to those used for the study of bacterial motility will be described. The diffusion of a chemical is a random process that follows well-known laws for diffusion. 


\section{The diffusion of glucose}

Instead of bacteria, ${ }^{14} \mathrm{C}$-glucose was introduced at one end of capillary tubes filled with medium, and then the tubes were incubated at room temperature. All the details of the procedure were otherwise identical to those described under Methods.

The diffusion of glucose measured by the complete assay. Figure 2 shows for several time points a complete assay of the diffusion of glucose, i.e. a determination of the distribution of glucose throughout the tube. The diffusion equation which applies to the present experimental conditions, where a thin layer of diffusion substance is placed at one end of a column of liquid, is the one of Ljunggren \& Lamm (1957):

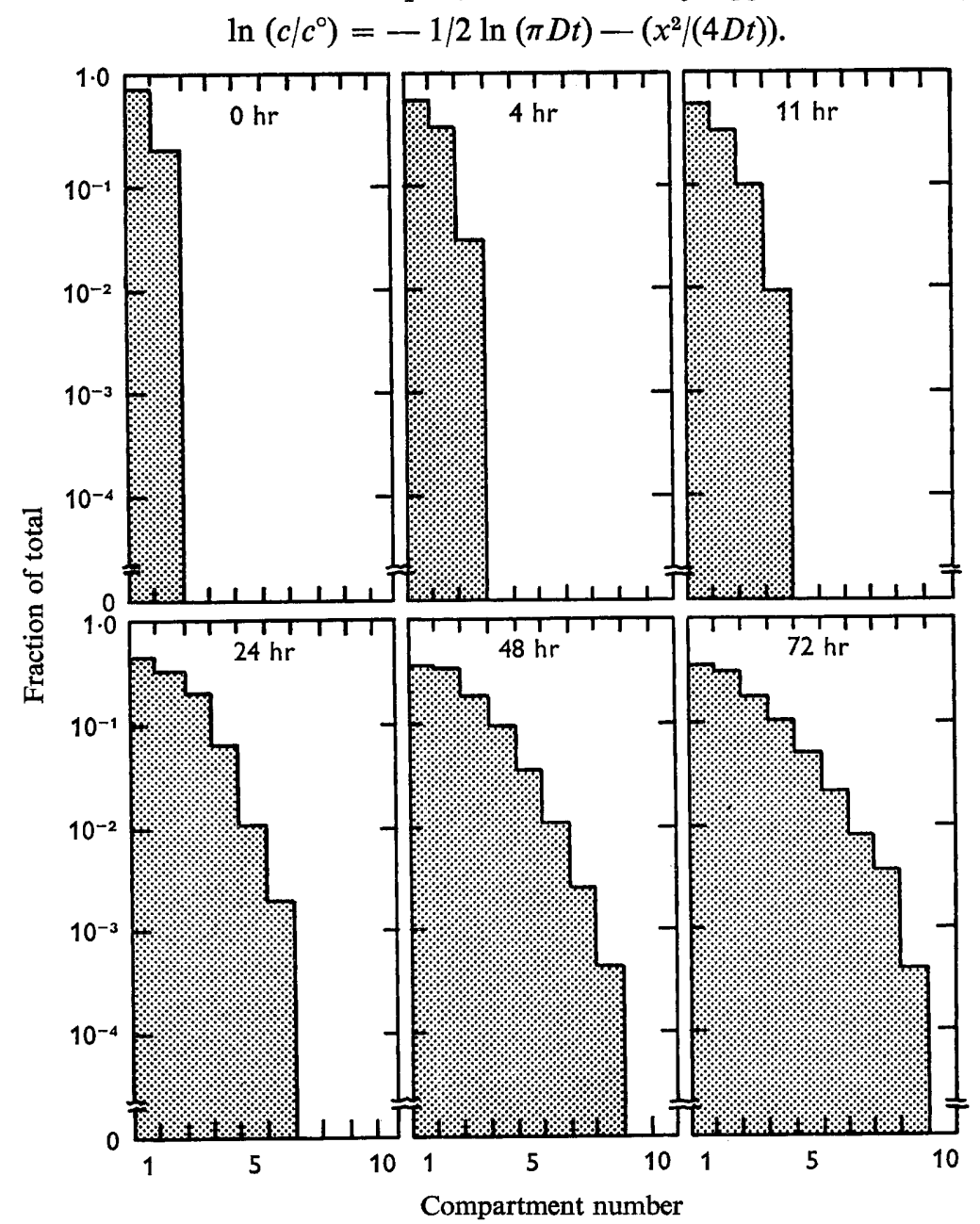

Fig. 2. The diffusion of glucose measured by the complete assay. Each capillary tube contained sterile $10^{-2} \mathrm{M}$-potassium phosphate $\left(\mathrm{pH} 7 \cdot 0\right.$ ) and $10^{-4} \mathrm{M}-\mathrm{EDTA}$. At one end 45,000 c.p.m. (0.034 $\mu$ moles) of sterile ${ }^{14} \mathrm{C}$-glucose was introduced. Bacteria were not added and were not involved in this experiment. After incubation at room temperature for various times, the tubes were fractionated into ten $0.8 \mathrm{~cm}$. compartments and the contents of each compartment were dried on a planchet and counted in a windowless gas-flow counter. See Methods for details. A value of zero means that no readily detectable radioactivity (less than 80 c.p.m.) was found in that compartment. 
Here $c^{\circ}$ represents the initial concentration, $c$ the concentration at any distance $x$ from the origin at any time $t$, and $D$ the diffusion coefficient. According to this equation, a plot of the logarithm of the fraction of the total radioactivity in each compartment $\left(\ln \left(c / c^{\circ}\right)\right)$ against the distance moved from the origin squared $\left(x^{2}\right)$ for any particular time should give a straight line whose slope is $-(1 / 4 D t)$. The data of Fig. 2, when replotted in this manner (Fig. 3), do indeed yield straight lines, and from the slopes of these lines $D$ was calculated as ranging from 0.017 to $0.022 \mathrm{~cm}$. ${ }^{2} / \mathrm{hr}$. This value is in good agreement with $0.024 \mathrm{~cm} .{ }^{2} / \mathrm{hr}$., a published diffusion coefficient for glucose at $25^{\circ}$ obtained by Gladden \& Dole (1953) with much more sophisticated techniques. We may conclude that under the experimental conditions used here the above equation correctly describes a process of random movement such as the diffusion of glucose.

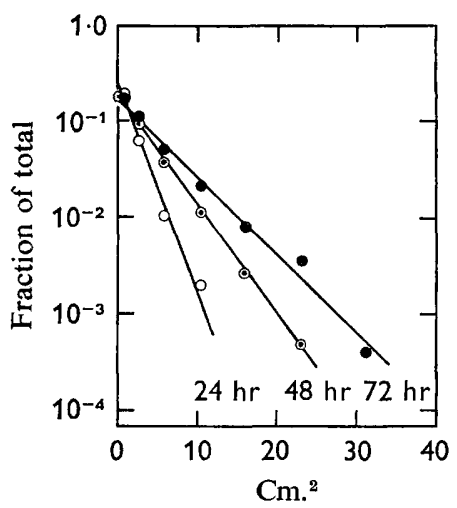

Fig. 3

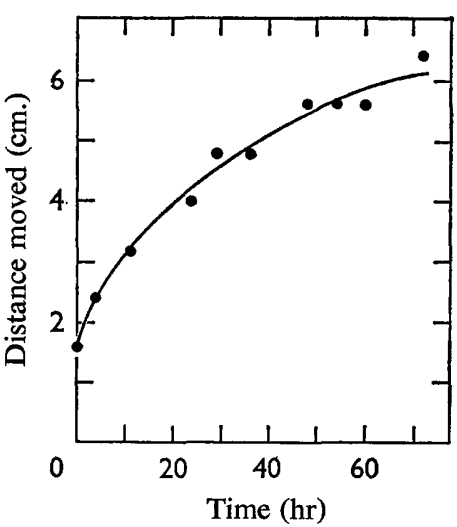

Fig. 4

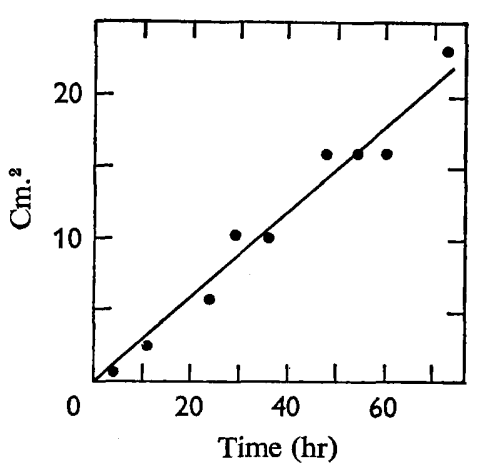

Fig. 5

Fig. 3. The data of Fig. 2 replotted. The abscissa plots the distance (cm.) moved away from the origin, squared. Since at zero time compartments 1 and 2 (the origin) were occupied, the length of two compartments $(1.6 \mathrm{~cm}$.) was subtracted in every case. This left only one point to plot for the $4 \mathrm{hr}$ data and only two points for the $11 \mathrm{hr}$ data; therefore no plots are presented for these time-points. In addition to the data shown for 24,48 and $72 \mathrm{hr}$, complete sets of data for $29,36,54$ and $60 \mathrm{hr}$ were also collected. These are not reported in order to keep the figure readable, but in every case the points fell very well on straight lines. $D$ calculated from the slope of each of these seven lines is $0.021,0.020,0.019,0.022,0.017,0.019$ and $0.018 \mathrm{~cm}^{2} / \mathrm{hr}$, respectively.

Fig. 4. The diffusion of glucose analysed by the frontier assay. The figure plots the farthest advance of at least 80 c.p.m. for each time-point. The data come from the complete assays described in Figs. 2 and 3.

Fig. 5. The data of Fig. 4 replotted. As in Fig. 4, except the ordinate represents $\mathrm{cm}^{2}{ }^{2}$ instead of $\mathrm{cm}$.; and $1.6 \mathrm{~cm}$. has been subtracted in every case since at zero time compartments 1 and 2 were occupied.

To study the effect of glucose concentration on the diffusion coefficient, capillary tubes were inoculated with $0.034,0.0043$, or $0.00063 \mu$ moles ${ }^{14} \mathrm{C}$-glucose, incubated for $77 \mathrm{hr}$ and then analysed. The diffusion coefficient was $0.020 \mathrm{~cm} . .^{2} / \mathrm{hr}$ in all three cases. As expected, the value found for the diffusion coefficient does not depend on the concentration of glucose, at least within the range studied.

The diffusion of glucose analysed by the frontier assay. The results from a complete assay include information about the 'frontier' of the migration-the farthest advance of at least 80 c.p.m., a minimum number of readily detectable counts. This information 
was collected from Fig. 2 and from the other complete assays mentioned in the legend of Fig. 3, and then replotted in Fig. 4. To apply equation (1) to the frontier assay, the equation can be rearranged to yield:

$$
x^{2}=-4 D t \ln \left(c / c^{\circ}\right)-2 D t \ln (\pi D t)
$$

In the frontier assay, $c$ is the minimum amount of radioactivity readily detectable ( 80 c.p.m.), $c^{\circ}$ is the amount of radioactivity added to each assay tube (45,000 c.p.m.) and $\ln c / c^{\circ}$ is therefore constant. Under conditions used here, the second term, $2 D t \ln$ $(\pi D t)$, becomes negligible compared to the first term, $4 D t \ln c / c^{\circ}$, and therefore a plot of $x^{2}$ against $t$ should give a straight line whose slope is $-4 D \ln c / c^{\circ}$. The data of Fig. 4 were accordingly replotted (Fig. 5). A straight line was indeed obtained, and $D$ can be calculated from the slope to be $0.015 \mathrm{~cm} .{ }^{2} / \mathrm{hr}$, in good agreement with the value obtained from the complete assay. This again supports the conclusion that equation (1) correctly describes a process of random movement such as the diffusion of glucose under the experimental conditions used here.

\section{Motility under conditions where the bacteria do not migrate in a band}

This section considers the motility of bacteria in the medium described under Methods. In this case, we shall see that the spreading of bacteria along the tube resembled a random process such as the diffusion of glucose but there were certain differences. A later section will concern itself with motility under conditions where the bacteria migrate in a sharp, easily visible, chemotactic band and do not at all behave like diffusing molecules.

Motility measured by the complete assay. Figure 6 shows complete assays of the movement of Escherichia coli at several times of incubation. This figure resembles Fig. 2 for the diffusion of glucose although the profile of the histogram is different. It is clear from Fig. 6 that initially all the bacteria were located in the first two compartments (the 'origin'); the remaining eight compartments were free of any viable bacteria. This shows that the sampling technique did not cause any objectionable amount of stirring.

To find how well equation (1) for diffusion (which is also the equation for random movement) describes the swimming of these bacteria, the data of Fig. 6 were replotted as $\ln c / c^{\circ}$ against $x^{2}$, as was done for the diffusion of glucose. The resulting curves (Fig. 7) were not straight lines; in the case of the diffusion of glucose, straight lines were obtained (Fig. 3). The explanation for the shape of the curves in Fig. 7 is not known; several possibilities will be considered in the Discussion.

Just as the slope in Fig. 3 for the diffusion of glucose was used to calculate a diffusion coefficient, so the slope in Fig. 7 (which is - $(1 / 4 M t)$ ) was used to calculate a motility coefficient, $M$. Although the slope of the curves in Fig. 7 is not constant, the smallest slope (corresponding to the fastest motility) was used to calculate motility coefficients of $0.57,0.48$ and $0.24 \mathrm{~cm} .{ }^{2} / \mathrm{hr}$ for the $1-, 2$ - and 5 -hr samples, respectively. In twenty different determinations this value ranged from 0.08 to $0.57 \mathrm{~cm} .{ }^{2} / \mathrm{hr}$, with an average value of $0.25 \mathrm{~cm} .{ }^{2} / \mathrm{hr}$.

To study the effect of inoculum size on the motility coefficient, $2 \cdot 2 \times 10^{6}, 1 \cdot 3 \times 10^{6}$, $7.7 \times 10^{5}, 2.6 \times 10^{4}$, or $2.3 \times 10^{3}$ bacteria were used in a 4-hr experiment. The motility coefficient was found to be $0.22,0.49,0.27,0.19$ and $0.18 \mathrm{~cm} .{ }^{2} / \mathrm{hr}$, respectively.

Motility measured by the frontier assay. The farthest point of advance of the bacteria 
can be obtained fron the results of a complete assay (see data of Fig. 6), but this information is much easier to get by means of the frontier assay. A typical result from frontier assay of the movement of bacteria is shown in Fig. 8. The top curve shows the farthest point of advance (the frontier) at various times for this motile strain of

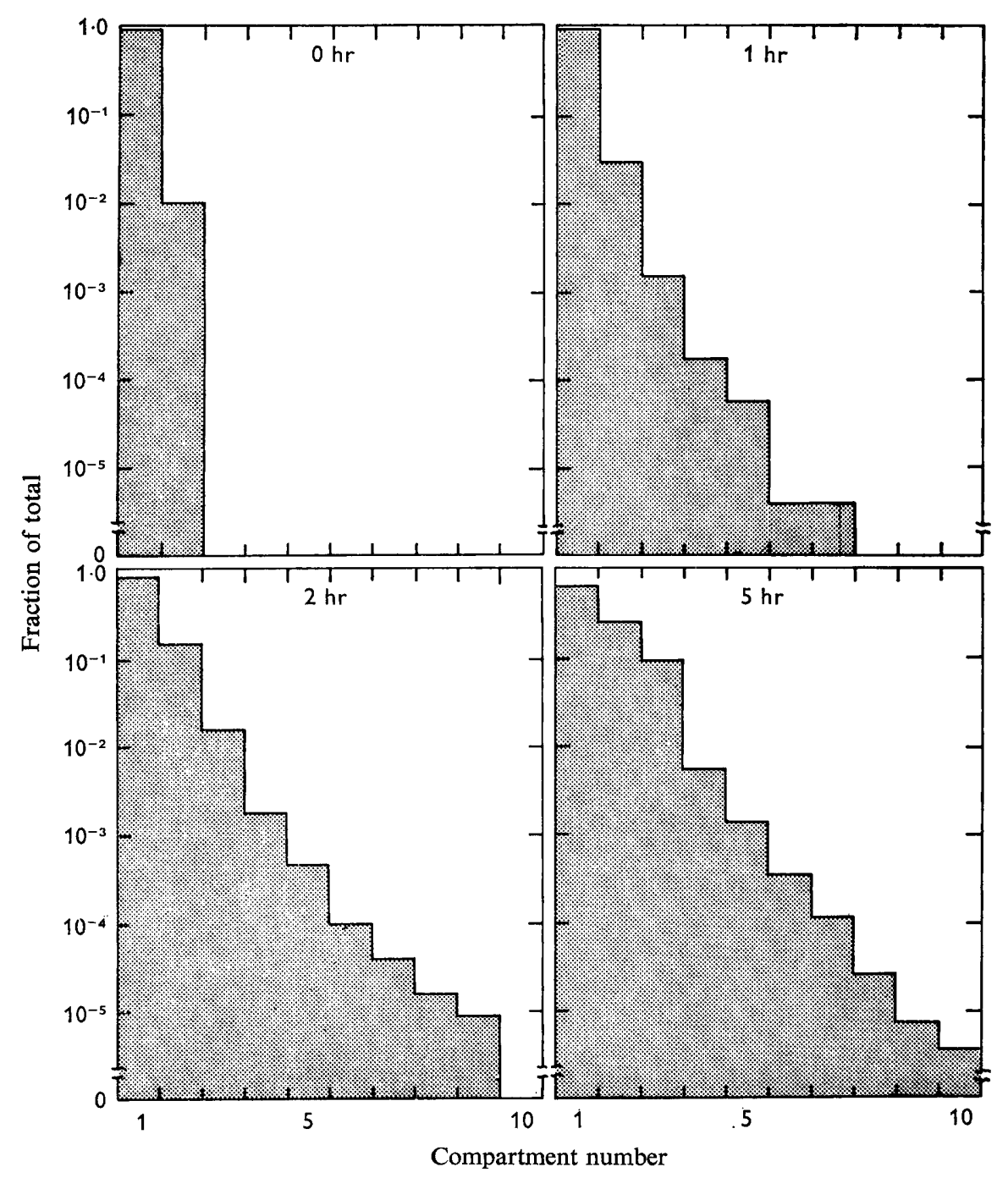

Fig. 6. The movement of bacteria under conditions where they did not migrate in a band, as measured by the complete assay. The capillary tubes contained the medium described under Methods. No methionine was added. After incubation at $37^{\circ}$ for $0,1,2$ and $5 \mathrm{hr}$, the tubes were fractionated into $0.8 \mathrm{~cm}$. compartments and viable Escherichia coli in each compartment were measured by plating and counting colonies. The total recovery of viable bacteria was $5 \cdot 5 \times 10^{5}, 2.4 \times 10^{5}, 3.4 \times 10^{5}$ and $1.1 \times 10^{6}$, at the respective times. These were not growth conditions since the required leucine, methionine and threonine were not added. See Methods for details. The figure includes the following data: at $0 \mathrm{hr}$, compartments $2-10$ contained no bacteria; at $1 \mathrm{hr}$ compartments 6 and 7 had 1 bacterium each, and compartments 8,9 and 10 contained none; at $2 \mathrm{hr}$ compartment 8 had 5 bacteria, 9 had 3, and 10 had none; at $5 \mathrm{hr}$ compartment 9 had 8 bacteria and 10 had 4 . 
Escherichia coli $\mathrm{K} 12$. This curve resembles the comparable curve for the diffusion of glucose (Fig. 4). The bottom curve of Fig. 8 shows that $E$. coli B, a non-motile strain, remained at the origin (it did so even at $24 \mathrm{hr}$, not shown in figure). This shows again that the sampling technique was reliable, and also that Brownian movement, diffusion, or convection of bacteria did not play a great enough role to interfere with the assay for motility.

To determine whether the equation for random movement (equation 2) describes the movement of these furthest moving bacteria, the data in the top curve of Fig. 8 were replotted in the same manner as was done for the diffusion of glucose. In this case,

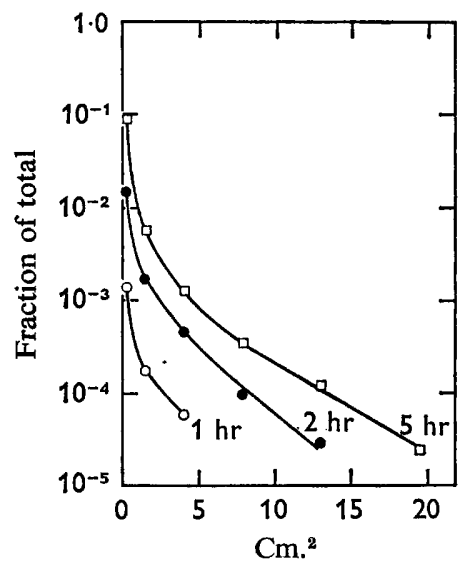

Fig. 7

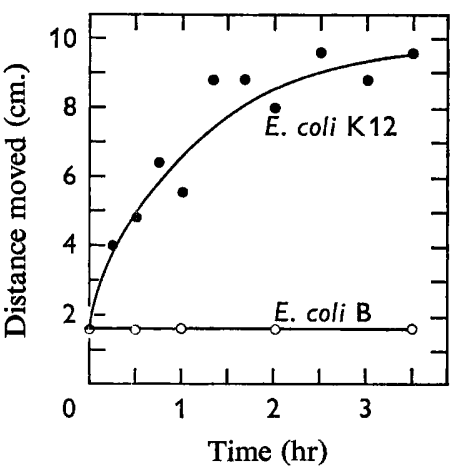

Fig. 8

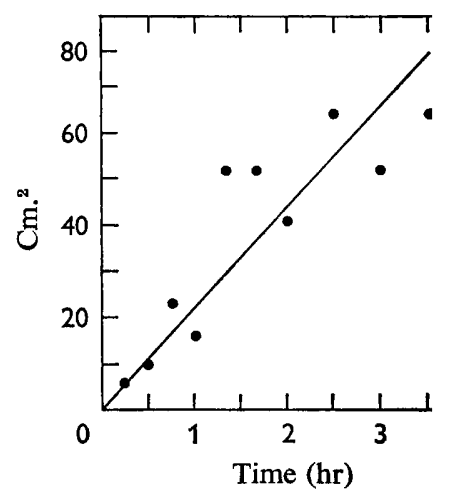

Fig. 9

Fig. 7. The data of Fig. 6 replotted. The abscissa plots the distance $(\mathrm{cm}$.) moved away from the origin, squared. Since at zero time compartments 1 and 2 (the origin) were occupied, the length of two compartments $(1.6 \mathrm{~cm}$.) was subtracted in every case. Values smaller than 10 bacteria/compartment are not included here. (These values are enumerated in the legend of Fig. 6). Such very low values tend to give scattered points in this kind of figure, probably because they are statistically so unreliable.

Fig. 8. The movement of bacteria under conditions where they do not migrate in a band, as measured by the frontier assay. Exactly as in Fig. 6, except that the frontier assay was used and more time-points were included. The farthest advance of the bacteria (the frontier) is shown for Escherichia coli $\mathbf{k} 12$, strain B 275, the motile strain used throughout this study, and for $E$. coli $\mathrm{B}$, a non-motile strain. In this experiment the tubes were longer than the usual ones.

Fig. 9. The data of Fig. 8 for Escherichia coli $\mathrm{K} 12$ replotted. As in Fig. 8, except the ordinate represents $\mathrm{cm} .^{2}$ instead of $\mathrm{cm}$. Since at zero time compartments 1 and 2 (the origin) were occupied, the length of two compartments $(1.6 \mathrm{~cm}$.) was subtracted.

$c$ in equation (2) is the minimum number of bacteria detectable (one bacterium), $c^{\circ}$ is the number of bacteria added to each assay tube $\left(10^{6}\right.$ bacteria), and $\ln c / c^{\circ}$ is therefore a constant. The second term of equation (2) becomes negligible as before, and a plot of $x^{2}$ against $t$ should give a straight line. Such a plot is shown in Fig. 9. Although the experimental points are somewhat scattered, a best-fitting straight line has been drawn. (In some experiments the points fell very much more closely on a straight line.) From the slope of this line (which is $-4 M \ln c / c^{\circ}$ ), a motility coefficient, $M$, was calculated to be $0.40 \mathrm{~cm} .{ }^{2} / \mathrm{hr}$. In seven different experiments this value has ranged from 0.13 to $0.40 \mathrm{~cm} .{ }^{2} / \mathrm{hr}$., with an average of $0.26 \mathrm{~cm} .{ }^{2} / \mathrm{hr}$. This is in agreement with the motility coefficient determined above from the complete assays. 
Motility under conditions where the bacteria migrate in a band

When the medium described under Methods was supplemented with methionine, a band of bacteria formed and travelled out into the tube. Such a band was clearly visible to the naked eye, and it has also been shown by photography, densitometry and microscopy (Adler, 1966a, b), as well as by assaying for viable bacteria along the tube, as will be seen. The band results from chemotaxis toward oxygen (Adler, 1966a,b), but the mechanism by which methionine promotes the formation of the band is unknown (see Discussion).

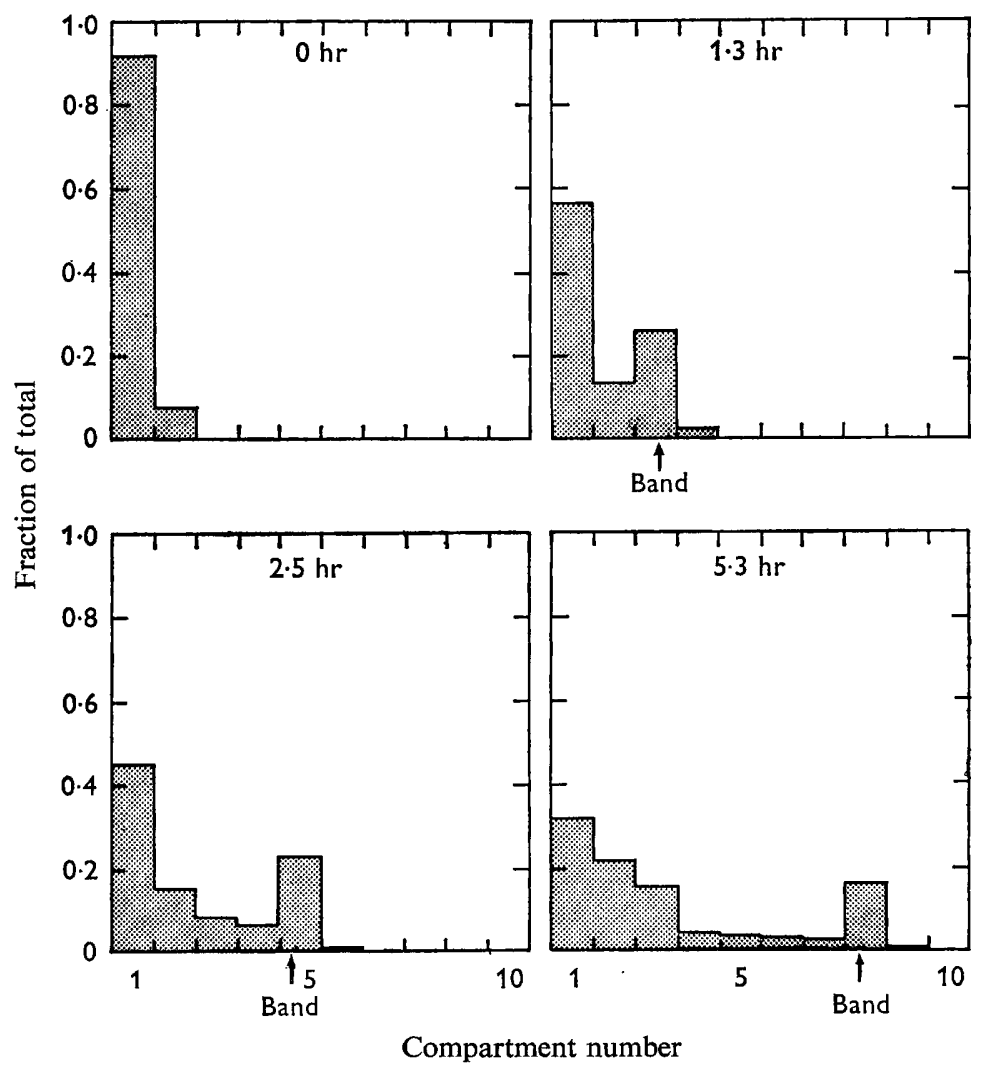

Fig. 10. The movement of bacteria under conditions where they migrate in a band (presence of methionine), as measured by the complete assay. The capillary tubes contained the medium described under Methods, $+3 \times 10^{-5} \mathrm{M}$-methionine. After incubation at $37^{\circ}$ for $0,1 \cdot 3,2.5$ and $5.3 \mathrm{hr}$, the tubes were fractionated into $0.8 \mathrm{~cm}$. compartments and the viable bacteria in each compartment measured. The total recovery of viable bacteria was $3.0 \times 10^{5}, 5.8 \times 10^{5}$, $8.2 \times 10^{5}$, and $9.6 \times 10^{5}$, at the respective times. The conditions used here were not conducive to growth since the additionally required leucine and threonine were not added. The bands were visible to the naked eye, and their location is shown by the arrows. See Methods for details.

Motility measured by the complete assay. Figure 10 shows complete assays of the movement of Escherichia coli under conditions where a band of bacteria formed and moved out into the tube. The band appeared as a peak fraction. Figure 10 is strikingly different in this regard from the comparable Fig. 2 for the diffusion of glucose or 
Fig. 6 for the motility of bacteria under conditions where they did not migrate in a band.

Motility measured by the frontier assay. Figure 11 shows the results of a frontier assay (top curve) of the movement of Escherichia coli under conditions where the bacteria migrated in a band, as well as a plot of the progress of the band itself (bottom curve). It may be seen that the band moved at a constant speed. The farthest point of advance of the bacteria, the frontier (top curve), was always some centimeters ahead of the band; the shape of this curve approximated a straight line in several experiments.

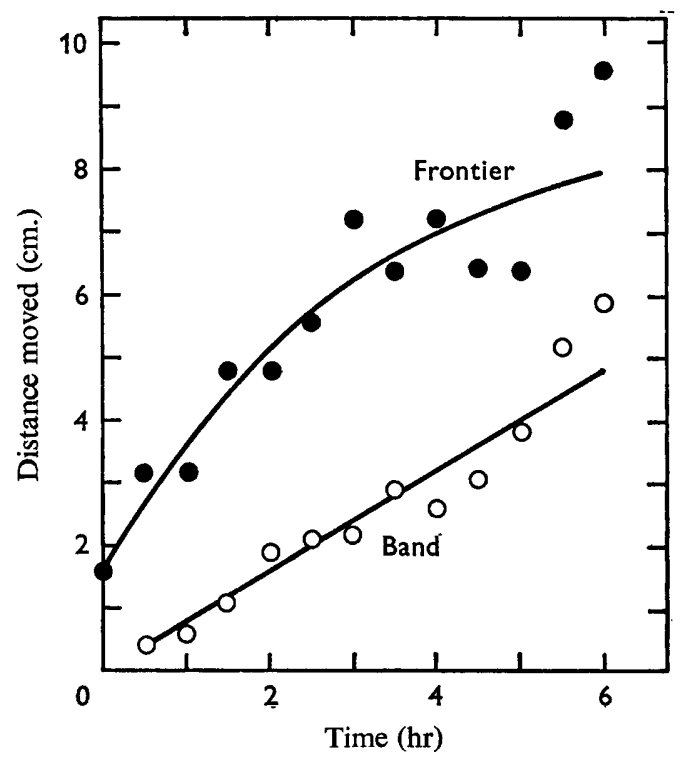

Fig. 11. The movement of bacteria under conditions where they migrate in a band (presence of methionine), as measured by the frontier assay. Exactly as in Fig. 10, except that the frontier assay was used and more time-points were included. The top curve shows the farthest advance of the bacteria (the frontier). The bottom curve shows the location of the visible band as measured with a ruler. In this experiment the tubes were longer than the usual ones.

\section{DISCUSSION}

Measurements of motility. The microscope allows a rapid and direct indication of motility. At a moment's glance one can estimate the velocity of the bacteria, the frequency of change of direction, the degree of co-ordination, or the fraction of a population that is motile. However, these observations are subjective and qualitative, and this tends to make such work with a microscope less credible and less easily reproduced by others.

In the work reported here the motility of bacteria was measured in capillary tubes by determining the distribution of bacteria throughout the tube (the complete assay) or simply by locating the point of farthest advance of the bacteria-the frontier of the migration (the frontier assay). These assays have the advantage of being objective and quantitative. They reduce the complicated motions of individual bacteria to a measurable number, the motility coefficient, and give a measure of the net forward velocity of the bacteria. They do not measure the actual velocity, because net forward movement includes numerous detours. Thus, a decrease in the net forward velocity might 
mean either a decrease in the actual velocity or an increase in the frequency of changes of direction. A bacterium that has moved out into the tube $4 \mathrm{~cm}$. in the first hour might have either an actual velocity of $4 \mathrm{~cm}$./ hr, if it was lucky in picking the right direction and in making no changes in direction or it might have a much higher actual velocity if it made very frequent changes in direction. The net forward velocity of the average bacterium, $\bar{v}$, equals $\sqrt{ }(2 M)$. For a motility coefficient, $M$, of $0.25 \mathrm{~cm} .{ }^{2} / \mathrm{hr}, \bar{v}$ is $0.7 \mathrm{~cm}$./ hr. By using a microscope and a clock, Ogiuti (1936) measured the actual velocity of Escherichia coli as $9 \mathrm{~cm} . / \mathrm{hr}$, and we measured the actual velocity as about $10 \mathrm{~cm} . / \mathrm{hr}$ with the strain and conditions used in this report.

The frontier assay described here has the advantage that it is much simpler to carry out than the complete assay. Although the frontier assay curve (top of Fig. 8) is not a straight line, it is nevertheless useful because one can state the distance that the bacteria have moved forward in a certain time and one can compare this distance for that time under a variety of experimental conditions. The curve can usually be changed into a straight line, however, by plotting the square of the maximal distance moved against time, as shown in Fig. 9. The slope of this line is then a convenient measure of the motility of the bacteria. The reliability of the assay has been confirmed by frequent use of the microscope: whenever an assay indicated either lack of motility or excellent motility, it was always possible to verify this by microscopic examination. Several demonstrations that bacteria with various degrees of motility really give various results in the frontier assay are included in the following paper (Adler \& Templeton, 1967).

On the other hand, the frontier assay has some disadvantages which may be mentioned. The outermost compartment that contains bacteria may have only a very few or even only one bacterium out of the million that were put into the tube. The result for any one time-point may then be determined by a very few individuals. This is the main cause for a very considerable amount of variability in this assay. Results which differ by one or even two compartments $(0.8$ or $1.6 \mathrm{~cm}$.) are not regarded as significantly different. While bacteria are usually found in every compartment from the origin up to a certain point, occasionally at the end away from the origin there is a skip which must have been produced by an especially lucky or fast bacterium. A policy of not scoring these skips was adopted, in order not to put reliance on these statistically insignificant events. The results obtained by the frontier assay depend on the number of bacteria put into the tube, as expected, so that it is necessary to keep the inoculum size approximately constant. For example, when capillary tubes were inoculated with $1.5 \times 10^{6}, 2.3 \times 10^{5}, 2.8 \times 10^{4}$ or $3.0 \times 10^{3}$ bacteria, the movement in $1 \mathrm{hr}$ advanced $5 \cdot 6,3 \cdot 2,2 \cdot 4$ and $0 \cdot 8 \mathrm{~cm}$., respectively. Similarly, the result would also be expected to depend on what fraction of the bacteria is motile. The shape of the frontier assay curve may also depend on whether or not chemotaxis is taking place, since bacteria will be held back in the chemotactic band.

Previous descriptions of quantitative assays for motility of bacteria should be mentioned, namely those of Clowes, Furness \& Rowley (1955), Gabritschewsky (1900), Liachowetzky (1910-11), Ogiuti (1936) and Shoesmith (1960). Of these, the first three are similar in principle to the frontier assay in that they measured the furthest point of advance of the bacteria (in a column of agar, Clowes et al. 1955; or on filter paper, Gabritschewsky, 1900, Liachowetzky, 1910-11), while the last two methods involved measurements with the use of a microscope. 
A comparison of random and non-random motility. When the bacteria do not migrate in a band, the motility qualitatively resembles the diffusion of glucose. The similarity is evident from a comparison of Figs. 2 and 6,4 and 8, and 5 and 9. This similarity in kinetics indicates that the bacteria were swimming randomly when they did not form bands, just as the glucose was diffusing randomly. By random swimming we mean that any direction of swimming is equally likely at all times throughout the container.

However, Fig. 3 for the diffusion of glucose has straight lines while Fig. 7 for the swimming of bacteria has curved lines. Several possible explanations for the curved lines can be offered. (1) The bacteria are heterogeneous with regard to their motility i.e. some swim faster than others. Preparations stained for flagella did show a range of 0-8 flagella/bacterium. Simple genetic heterogeneity was eliminated, since descendants from one of the farthest-moving bacteria again yielded the same curves as shown in Fig. 7. (2) The conditions in the capillary tube are heterogeneous. The crowded condition near the origin leads to rapid exhaustion of oxygen and substrates and to extensive accumulation of waste products, and is therefore less favourable to motility than the relatively unpopulated medium further out. For example, it is known that swimming in presence of serine is slower anaerobically than it is aerobically (Adler \& Templeton, 1967). (3) Crowding at the origin causes frequent collisions of bacteria and this decreases the net forward velocity near the origin.

Chemotaxis in bacteria has been known ever since the end of the nineteenth century when Engelmann, Pfeffer and others observed chemotaxis towards oxygen, minerals and organic nutrients microscopically (for a review see Weibull, 1960). In 1893 Beijerinck demonstrated macroscopically chemotaxis towards oxygen by showing that a variety of motile bacteria placed at the bottom of a test-tube filled with water formed a sharp easily visible band that ascended until it came to a stop near the meniscus. More recently, Sherris, Preston \& Shoesmith (1957) and Baracchini \& Sherris (1959), with capillary tubes instead of test-tubes, confirmed and extended these results.

The band of bacteria which formed in presence of methionine, described above, was due to chemotaxis towards oxygen. Measurements of oxygen and serine (Adler, $1966 a, b)$ have shown that this band travelled along consuming all the oxygen to oxidize a part of the serine.

When chemotaxis was taking place (Fig. 10), the kinetics of movement did not resemble a random process like the diffusion of glucose (Fig. 2). The bacteria (at least those in the neighbourhood of the band) were not swimming randomly. By this we mean that the gradient of oxygen which the bacteria created in the vicinity of the band somehow influenced the bacteria to swim preferentially in the direction of increasing oxygen concentrations. Microscopic examination showed that the bacteria in the band swam in a short line and then stopped for an instant. The appearance was one of very rapid and highly jerky motion. This suggests that an 'avoiding reaction' (or 'shock reaction') was taking place (see Weibull, 1960): whenever a bacterium enters a region of lower oxygen concentration, it stops for an instant and then goes off in a new randomly chosen direction (or in some species it backs up). When it finds itself at a higher oxygen concentration, it does not change its direction. The net result is a nonrandom swimming which causes the organisms to vacate a region of low oxygen concentration and to accumulate where the concentration of oxygen is higher. (Actually, very high concentrations are also avoided.)

The mechanism by which methionine promotes the formation of the band remains 
to be elucidated. Judged by microscopic examination, the motility is just as vigorous with or without methionine. However, in the absence of methionine the bacteria swam in long straight lines with only rare gradual changes in direction, instead of in a jerky manner. This suggests that the avoiding reaction was not taking place when methionine was absent. The strain of Escherichia coli used for these studies requires methionine for growth, but it also requires leucine and threonine for growth and these were not needed for the formation of bands. A prototrophic strain of $E$. coli, such as w3110, formed bands without the addition of any methionine.

We thank Drs R. L. Baldwin, W. W. Cleland, H. Echols and H. C. Kranzer for valuable advice and discussions. This work was supported by grants from the U.S. National Science Foundation, the National Institutes of Health, and the Graduate School of the University of Wisconsin.

\section{REFERENCES}

Adler, J. (1966a). Chemotaxis in bacteria. Science, N.Y. 153, 708.

ADLER, J. $(1966 \mathrm{~b})$. The effect of amino acids and oxygen on chemotaxis in Escherichia coli. J. Bact. 92, 121.

Adler, J. \& Templeton, B. (1967). The effect of environmental conditions on the motility of Escherichia coli. J. gen. Microbiol. 46, 175.

Baracchini, O. \& Sherris, J. C. (1959). The chemotactic effect of oxygen on bacteria. J. Path. Bact. 77, 565 .

Clowes, R. C., Furness, G. \& Rowley, D. (1955). The measurement of speeds of motility in Escherichia coli. J. gen. Microbiol. 13, i.

GABRITSCHEWSKY, G. (1900). Über active Beweglichkeit der Bakterien. Z. Hyg. InfektKrankh. $35,104$.

Gladden, J. K. \& DOLE, M. (1953). Diffusion in super-saturated solutions. II. Glucose solutions. J. Am. chem. Soc. 75, 3900.

KAISER, A. D. \& Hogness, D. S. (1960). The transformation of Escherichia coli with deoxyribonucleic acid isolated from bacteriophage $\lambda \mathrm{dg}$. $J$. molec. Biol. 2, 392.

LEDERBERG, J. (1950). Isolation and characterization of biochemical mutants of bacteria. Meth. med. Res. 3, 5.

LiACHOWETZKY, M. (1910-11). Eine neue Methode zum Studium der lokomotorischen Funktion der Bakterien. Zentbl. Bakt. ParasitKde, I Abt. Orig. 57, 180.

LJUNGGREN, S. \& LAMM, O. (1957). Diffusion from a bottom layer; diffusion with moving boundaries. Acta chem. scand. 11, 340.

OGIUTI, K. (1936). Untersuchungen über die Geschwindigkeit der Eigenbewegung von Bakterien. Jap. J. exp. Med. 14, 19.

Sherris, J. C., Preston, N. W. \& Shoesmith, J. G. (1957). The influence of oxygen and arginine on the motility of a strain of Pseudomonas sp. J. gen. Microbiol. 16, 86.

Shoesmith, J. G. (1960). The measurement of bacterial motility. J. gen. Microbiol. $22,528$.

Weibull, C. (1960). Movement. In The Bacteria. Ed. by I. C. Gunsalus, and R. Y. Stanier, vol. 1, p. 153. New York: Academic Press. 